\title{
Study on Innovation and Construction of Government Model of Regional Innovation System
}

\author{
Xiaoming Qiao \\ Journal Editorial Department, Yunnan Normal University, Kunming, Yunnan, 650092
}

Keywords: Innovation, Regional Innovation System, Government of RIS

\begin{abstract}
This paper makes clear the essence of innovation and innovation-driven development on the theoretical research and practical exploration and combs opinions on the research of regional innovation system. Then the connotation of regional innovation system is defined. Meantime, the paper studies the construction and government model of regional innovation system. Based on Schumpeter's innovation theory, Potter's diamond model theory and government model of RIS, and other proposals are given.
\end{abstract}

\section{Introduction}

Innovation, innovation-driven development is a hot word both in academia and in practice. Innovation and Innovation Driven Development by raising productivity, we will solve the problem of diminishing returns on the factors of production and the bottleneck of natural factors in economic development. Its purpose is to solve the problems of uncoordinated, unbalanced and unsustainable economic development. After experiencing the development stage driven by factors and investment, the developed countries attach great importance to the driving role of scientific and technological innovation in economic development. According to a Bloomberg survey, the top ten most highly-tech companies in the global market in 2015, the United States has nine. The Organization for Economic Co-operation and Development (OECD), in tracking the economic development of its member states, found that knowledge and information contributed half of its GDP to most member countries. Innovation hair how to unify the context? What is the specific direction of innovation-driven development? How to enter the innovation-driven development model, innovation-driven development to achieve the standards? There is no unified definition. Domestic scholars mainly interpret and evaluate innovation-driven development from the meaning of innovation or technological innovation, which obscures the essence of innovation-driven development and can not accurately reflect the essence of innovation-driven innovation. Innovation is not equivalent to science and technology innovation. Innovation drive is not equivalent to innovation ability evaluation or economic development evaluation. Few scholars based on the practice of innovation-driven development in foreign countries carry out empirical research. The fundamental reason for the "multi-perspective" and confusion existing in the research on innovation and innovation-driven development lies in the non-uniformity of the context of the two connotations. Research on innovation and innovation-driven development should return to its essence and define a clear standard of achievement. Domestic scholars on innovation, innovation driven development of academic research theory rooted in Bear Peter's economic development theory, Porter's diamond theory system 1.

How to achieve innovation-driven development? Different schools of thought and domestic and foreign development practices provide different path models. According to the difference between the role of government and the market in economic development, they are divided into different schools, such as the neoclassical school and the new bear-petri school. The Neoclassical School emphasizes the government's indirect intervention and guidance in the innovation market. The New Bears School emphasizes the market structure of enterprises. The best known is the school of innovation system proposed by Lundwal in 1985, which promotes the innovation and development through the establishment of an innovation system to promote the interaction of various elements in the system, to form a system of synergy and overall effectiveness. An important path driven by 
innovation is to build an innovation system. Through effective management of the innovation system, the goal of system efficiency and innovation-driven development can be achieved. The research object of national innovation system and technological innovation system is more clear. However, what is the regional innovation system? There are still some differences in understanding how the regional innovation system effectively manages the interaction of the main elements of innovation.

\section{Innovative, innovative concept driven by the clear}

The word innovation in all fields have the use of generalization, such as academic innovation, theoretical innovation. However, there is no unified definition of context. "Innovation" was first proposed by Xiong Pitt in "Economic Development Theories" published in 1921. 2 It is believed that the so-called "innovation" is the "establishment of a new production function," which sets an unprecedented standard on factors of production and production Conditions of the "new combination" into the production system. "Innovation" is the essence of economic development, the concept of economics, not the concept equivalent to scientific and technological innovation and technological innovation. Xiong Peite stressed that "entrepreneurs" are the main promoters and organizers of "innovation", "new combination of production factors" and "economic development." "Entrepreneurs" achieve economic development by "constantly reforming the economic structure from the inside, constantly destroying the old, and constantly creating new structures." We must break the "equilibrium" state of "circulation and circulation" in the production process. Bear Pitt's "Innovation" Neither the new factor of production nor the "new combination" of production conditions must be introduced into the production system in order to achieve development. In the final analysis, "innovation" is to increase productivity and promote enterprise development. Bear Pitt said "innovation", "new combination" or "economic development" includes five situations: (1) the introduction of new products; (2) the introduction of new technologies, that is, new production methods; (3) the opening up of new markets; (4) controlling the source of new supply of raw materials; (5) realizing the new organization of the enterprise. This is also product innovation, technological innovation, market innovation, business model innovation, management and institutional innovation.

\section{Regional innovation system connotation and construction}

The fundamental way of innovation-driven development is to introduce new factors of production into the enterprise, activate the innovation inventory of the enterprise and increase the productivity through the interaction of all the key elements of the diamond model. How can the various key elements interact effectively to form a diamond model? Lundvall proposed the development of a national innovation system in 1985. The school pointed out that 4 , the system rules established by the state will affect the use of innovative resources, interactive subjects, network and operating mechanism. This requires that the main body of the innovation factor or the subject that creates the demand conditions, such as enterprises, universities, research institutes, intermediaries, government, the public and other subjects in a specific institutional environment synergies to achieve the overall effectiveness of innovation system to achieve innovation-driven development The goal.

So what is the innovation system? How to build? In terms of hierarchy, there are the global innovation system, the national innovation system and the regional innovation system. In terms of content, there are the technological innovation system, the scientific and technological innovation system and the urban innovation system. Among them, the contents of the system of technological innovation and the system of scientific and technological innovation are more specific and specific; the study of the system of national innovation is relatively more, with a clear direction and more mature research; the system of regional innovation is an extension of the national innovation system and its application in specific regions; The result is also more substantial. However, is the concept of a regional innovation system an entity or a virtual one? Comparing the existing research results, 
we find that the concept of regional innovation system is mostly constructed in the research, which changes with different research perspectives and concerns.

\section{Regional innovation system of governance options}

Effective governance of regional innovation systems facilitates the formation of innovative diamond-driven models. The synergies between the main elements of the regional innovation system (universities, research institutes, enterprises, etc.) and non-principal elements (policies, systems, laws, contracts, etc.) correspond to the interaction between the key elements of the diamond system and achieve innovation-driven development. The main elements of the regional innovation system Universities and research institutes guarantee and support the formation of human resources and knowledge resources in the "production factors" of the diamond model; the financial institutions provide capital resources in "production factors"; the government and innovation intermediary organizations support the diamond model In the infrastructure construction and "demand conditions" form; enterprise self-innovation and the construction of modern enterprise system corresponding to the key elements of "corporate strategy, enterprise structure, competition in the same industry"; the main body of innovation and coordination of key elements of the industrial clusters to promote Cultivation and formation of industry chain.

How to manage regional innovation system? According to the governance practices of developed countries, governance is mainly put forward to solve the problems of government failure and market failure. Multiple governance bodies, the core of governance in the democratic consultation, governance tools and diverse. The governance of the innovation system in developed countries is mainly a multi-level governance model with multiple subjects. From different disciplines and the government's role in the innovation system, the degree of strength is divided into different governance models.

Government and the market in the innovation system to play a role in the strength of the governance model. According to the government's influence on the innovation system, the strength and weakness can be divided into different governance modes: government governance mode, collaborative governance mode and market governance mode. Government governance mode is the construction of government-led innovation system and governance of innovation system through system, policy, law and administration. Market governance model that the innovation system is entirely market behavior, the governance of innovation system dominated by the market. Collaborative governance model is the synergetic governance of all subjects within the innovation system and the government, emphasizing the synergetic development among the knowledge innovation system, technological innovation system and market innovation system under the democratic consultation and nested system of innovation. Market-led innovation system governance model has its own shortcomings. In the early days of its formation, the innovation system needs the help of government forces. From innovation to commercialization, it can hardly be realized by the operation of enterprises in the market. Government-led innovation governance model easily lead to the lack of vitality of the innovation system, it is difficult to form a system of innovation system efficacy. Collaborative governance model is the mainstream development trend of innovation system governance, representing the direction of innovation system governance change. The co-governance model emphasizes the use of compulsory governance tools such as policy and nexus with negotiated governance tools such as contracts, contracts, and negotiations. Collaborative governance model not only emphasizes the introduction of "innovation" increment such as knowledge and technology, but also focuses on the new combination of markets, products and information. Through the synergistic effect of innovations such as knowledge, technology and market, innovation cooperation is formed.

Management of governance framework. On how to achieve innovation governance system, from the perspective of management to build an analysis and governance framework. Mainly from three aspects of the governance body, governance mode, governance mechanism, governance objectives, governance evaluation of the regional innovation system, from the organization, tools and processes. 
At present, the regional government in our country plays an important role in the governance of the innovation system. Professor Chen Jin pointed out in the "three-helix innovation model" of translation that Ezkowiez has designed the innovation system based on triple helix in the practice of innovative regions, it proves that party organizations have played an important role as "regional innovation organizers." Figure 1 is an example of Anhui Province's regional innovation system, showing the governance structure of Anhui provincial government's regional innovation system.

\section{Inspiration}

China has entered the bottleneck of its development from a "latecomer" country that has obvious comparative advantages such as low cost of human resources and rich natural resources. The development that relies on "market-for-technology" and "land-for-technology" "There is a" poor minimum development "5. Only by realizing the advantage of backwardness to the "magnificent turnaround" of the starting edge can the developed countries be ruled out, and these are based on major technological changes and market innovations. The inspiration to the construction and management of regional innovation system is:

Scientific and technological innovation is the core support. It is the key to realize innovation-driven development by introducing scientific and technological innovations into the production system. Scientific and technological innovation is an important tool for realizing innovation-driven development. It is not an end. The achievements of scientific and technological innovation can not be driven by innovation without the introduction of production system. Innovation-driven assessment and policy guidance can not naturally evaluate the evaluation of science or technology or the evaluation of technological innovation as an innovation driven development. Xi Jinping pointed out that innovation is not a publication of an article, and a patent application is done. Innovation must be implemented to create a new growth point and turn innovation into a real industrial activity. Xi Jinping also used the example of the Qing Dynasty to profoundly analyze the "Needham Puzzle." "Science and technology must be combined with social development. To learn more and to put others aside is just a curiosity. It is only a Masonic, even as a trick, Impossible to have a role in the real world. "Science and technology innovation is the foundation and core, the introduction of innovative achievements into enterprises to transform is the key, are indispensable. China's region should be injected into the innovation system through limited financial resources so as to optimize the development and layout of the innovation system. It should also invest more in basic research to enhance its ability to innovate. It should also pay attention to bridging and promoting the transfer and transformation of science and technology achievements and building a scientific and rational scientific result Assessment mechanism and the transfer of scientific and technological achievements into the system of incentives; guide the whole society to innovate resources gathered in enterprises to accelerate the spillover and conversion of knowledge and technology, spawning batch of emerging high-tech enterprises; for the regional innovation system, talent pooling and industrial clusters to nurture and develop Good financial guidance and financial capital support. For example, in Anhui Province's practice of "innovation in innovation", Hefei focused on building the National Science Center of Hefei. With the cluster advantages of major science projects, Anhui Province strengthened the construction of four levels. The core is to promote basic scientific research and multidisciplinary research.

The construction and management of regional innovation system should also focus on the "new combination" of the stock of enterprises. Through the combination of a series of policies and systems to create an environment that encourages enterprises to innovate, and promote enterprises to become both the main body of technological innovation and product innovation, but also promote the optimization and innovation of enterprise management structure, institutional innovation, strategic innovation, market innovation Wait. Encourage enterprises in science and technology innovation activities in the enthusiasm to protect the enterprise in the regional innovation system, the core position, give play to the enterprises in the innovation and resources allocation and innovation decision-making participation and status. Support enterprises to become the main body of technological innovation decision. Important decisions involving innovation and the national 
economy should pay attention to the participation of business personnel. Through the business innovation alliance, innovation intermediary organizations, etc., to promote the formation of regional innovation industrial clusters and the development of the industrial chain.

The construction and management of the innovation system should pay attention to giving full play to the function and function of each innovation subject and the governance characteristics of the innovation system. At the same time, it is necessary to pay attention to the collaboration and interaction between the subjects and promote the regional innovation system to form a diamond model. The governance of regional innovation system is diverse: government, universities, research institutes, enterprises, etc.; diversification of governance tools: both mandatory tools such as laws and regulations, but also democratic consultation tools such as contractual contracts; governance processes and mechanisms More flexible and diverse: including structured government processes and unstructured market processes. The construction and management of regional innovation system should not only promote the construction of modern governance system in enterprises, universities and research institutes, strengthen their own governance and innovation, but also fully mobilize the active participation of all parties in the governance of the innovation system. We should give full play to the main role of enterprises in the organization of innovation decision-making, achievement transformation and innovation activities, and establish and cultivate a system of modern innovative intermediary organizations with service specialization, functional socialization, organizational networking and operation standardization.

In addition to the four key elements of a complete diamond system, there are opportunities and governments, paying attention to "opportunities" and giving full play to the role of government. Opportunity refers to major technological changes. We must pay attention to major technological innovations both at home and abroad and form the "external economic" environment for regional innovation and development. Attention should be paid to the key role of the government in the governance of the regional innovation system as well as the mode of action, content and boundaries. The governance of the innovation system by the government is also a key way for the government to reform the science and technology system to further free the productivity of science and technology. The government's governance tools are mainly structural policies such as policy regulation and guidance, governance process emphasis on proceduralization, and tools primarily on a formal basis. Governance includes the provision of innovative policies, including the formulation, implementation and guarantee of policies, systems and laws. In the reform of the supply side of innovation policy, the government pays attention to acting as a think tank, pays attention to the policy needs of innovation entities such as enterprises, and guarantees the legal and institutional participation of non-governmental organizations when setting the policy agenda. Increase innovation and public infrastructure construction, platform construction and innovation demonstration park construction. Through various types of innovation parks, innovation and development of experimental zone construction, gathering innovative elements, cultivate innovative industrial clusters. Do a good job in innovation and public service innovation system of cooperation and exchange. In addition, we should pay attention to the government in the process of innovation system governance process, the governance of regional innovation system does not mean that the government governance innovation.

\section{References}

[1] Wang Haiyan, Zheng Xiumei. The Theoretical Foundation, Connotation and Evaluation of Innovation-driven Development [J]. Soft Science of China, 2017 (01): 41-49.

[2] Joseph Schumpeter. Economic Development Theory [M]. Beijing: Commercial Press, 1990.24.

[3] Michael Porter. National competitive advantage (upper and lower) [M]. Beijing: CITIC Publishing House, 2012:79.

[4] Xue Lan, Liu Xielin, Mu Rongping translation. OECD China's innovation policy research report [M]. Beijing: Science Press, 2011:65. 
[5] Zhang Laowu. On the development of innovation driven [J]. China Soft Science, 2013 (01): 1-5.

[6] (United States) Henry Ekukowitz; Chen Jin translation. Three spiral innovation model [M]. Beijing: Tsinghua University Press, 2016:54. 